\title{
"UN VOCABULAIRE FORESTIER"
}

(A Forestry Vocabulary)

In its first number, which appeared in February, 1939, "La Forêt Québecoise" published the first pages of a forestry vocabulary of some ten thousand words under the authorship of a technical committee of the Association of Forest Engineers of the Province of Quebec. Mr. Eric Hudon was Chairman of that committee.

Each subsequent number contained several pages of this vocabulary, until the month of October, 1943, when in the third number of its sixth volume, the "Forêt Québecoise" published the thirty-one last pages of the French part of the vocabulary.

The Council of the Association of Forest Engineers, on the suggestion of several of its members, then considered the question of an edition for more convenient reference.

The original text was revised and corrected by a group of engineers, and an English section was added.

The Association of Forest Engineers of the Province of Quebec is now pleased to offer to all educators, students, engineers, technicians, industrialists, woodworkers and forest workers, and to all those who may be interested, the first edition of its "Vocabulaire Forestier" which has just been published.

The "Vocabulaire Forestier", 504 pages, is a French-English dictionary. The French section gives the definition and translation of 11,304 words, terms and expressions used in forestry and all its relative branches, with in addition more than 2,600 synonyms and antonyms. Foresters and others will find in the English section the practical answer to many difficulties in translation. This second part of the vocabulary contains 10,204 English words and expressions with their French equivalents. The person consulting this work can then, with the help of these French translations, refer to the French section and find the required definition.

Furthermore, the "Vocabulaire Forestier" is the first and only technical forestry vocabulary to contain most of the local "canadianisms" currently in use in the colorful language of our forest workers.

The financing of this publication and its sale have been entrusted to a co-operative society comprising some forty forest engineers, under the name of "La Forestiere".

Anyone wishing to obtain a copy of the "Vocabulaire Forestier" should address his order to "La Forestiere", P.O. Box 215, Upper-Town, Quebec, this agency being the sole distributor of the publication. The order must be accompanied by a postal note for $\$ 5.00$ plus $\$ 0.15$ for mailing charges.

The publication of this forestry vocabulary will undoubtedly promote the advancement and popularization of the different branches of the science of forestry in the Province of Quebec, and the Association of Forest Engineers takes this opportunity of extending its thanks to all those who have contributed to its realization, with particular mention of Messrs. Eric Hudon, Ls.-Z. Rousseau and Roch Delisle, to whom the successful outcome of the undertaking is mainly due. 